\section{The Origin of Radium.}

Is an earlier communication to NATURE (Sepiember 26 , p. 544) I mentioned some experimental proof which had been obtained of the existence in uranium minerals of a new radio-active element differing from those which have previously been identified. More conclusive evidence of the individuality of this new substance has now been obtained through the examination of the properties of its a radiation. The $a$ rays which it emits are much more readily absorbed by aluminium than the $a$ rays from polonium, with which it has been directly compared. Their apparent range in air determined by the scintillation method is less than 3 centimetres, and a more accurate determination is somewhat difficult, since it has not yet been found possible to obtain the new substance entirely free from thorium. Certain operations are now being carried out with considerable quantities of a uranium mineral containing no thorium which it is hoped will result in the separation of a highly active preparation of the new body free from other radio-active substances. The short range of the a particles is, however, sufficiently characteristic to serve as a definite means of identification.

The new substance also gives out a $\beta$ radiation which is much less penetrating and more easily absorbed than that from uranium, the value found for the coefficient of absorption being about $\mathrm{r} .8$ for aluminium.

Experiments which have been carried out with the view of obtaining a quantitative separation of this new element from small quantities of very pure uraninite have given results which are in good agreement with one another, and which indicate that the activity of the new element in equilibrium with radium is about 0.8 of the activity of the radium itself with which it is associated. This is about the value to be expected if the new substance is intermediate between uranium and radium when the ranges of the $\alpha$ particles are taken into consideration.

The name "ionium" is proposed for this new substance, a name derived from the word "ion." This name is thought to be appropriate because of the ionising action possessed by this element in common with the other elements which emit a radiations.

Bertram B. Boltwood.

Slnane Laboratory, Yale University, New Haven,

Conn., September 21

\section{Excretion from Plant Roots.}

THis subject, discussed at intervals over the greater part of a century, has been recently revived. Mr. Pickering has suggested that the effect produced by one plant on another is probably due to the indirect action of bacteria. Dr. Russell attributes it to chemical changes in the soil, whilst Schreiner and Reed in America (Bulletin of the Torrey Botanical Club, June) and $\mathrm{Mr}$. Fletcher in India have described experiments tending to show that some deleterious substance is excreted from the root. The questions incidentally raised by these several experimenters are not all identical, because, as Mr. Pickering points out, his work has to do with initial stages of growth, while that of others relates to subsequent development.

So far as excretion is concerned, it seems to be almost excluded as a possible explanation, because it would demand open orifices in the root which do not exist. There is nevertheless another line of thought which may have a more likely bearing on the subject. I refer to ionised changes such as occur when hydrogen chloride forms inside the red-blood corpuscle and sodium carbonate on the outside, or when sodium hydrate forms in the blood and hydrogen chloride in the stomach. Both these changes are due to the selective power of the living cell wall; and similarly it is probable that the cell wall of the root exercises a like property, and that the substances called plant foods do not pass into the root cell as such. but suffer change. Thus it is explained why the liquid outside the root becomes more basic, that on the inside more acidic (Hall and Miller, Proc. Roy. Soc., I905).

May it not be equally possible that, owing to such changes, harmful substances may be formed in the soil solution?

Agricultural Research Institute, Pusa, Bengal.

\section{Pleochroic Halos.}

In the March number of the Philosophical Magazine I gave reasons for believing that the pleochroic halos of certain micas are referable to the radio-activity of the enclosures which are invariably associated with the halos. I cited in favour of this view the facts that all minerals definitely recognisable as forming the centres of halos are radio-active; that the perfect sphericity of the halo in a medium such as mica precluded any explanation involving diffusion or segregation of colouring matter, and that there was a very exact agreement between the known effective penetrability of $\alpha$ rays in media of this density and the maximum radius attained by the halo. I subsequently found; by examination of specimens kindly lent to me by Dr. Teall, that the same reasoning was applicable to halos formed in cordierite.

When first conceiving this idea, I started experiments on cleavage flakes of biotite to ascertain if halos could be induced by enclosing between the flakes specks of radium bromide. For some two months I kept these preparations under observation, but no change was apparent. They were then put aside in view of experiments which necessitated my abstention from any contact with radio-active preparations.

Within the last few days Dr. Teall has directed my attention to the (independent) work of $O$. Mügge, of Königsberg i. Pr., which appears in the July number of Centralbl. für Min., in which a coloration was successfully induced in cordierite by application of radium, a coloration agreeing in properties with the halos in cordierite. This sent me back to my slides, and I find that a brown coloration has now developed around the larger radium specks. These stains have all the appearance of halos save that the radius is greater and the boundary less defined, differences at once explicable on the fact that the rays here travel in air before entering the mineral, and hence possess a greater, and at the same time a less sharply defined, "range of effectiveness. The coloration is faintly pleochroic, the direction of greatest absorption agreeing with that of some naturally occurring halos present in the flakes.

There is, of course, nothing in these observations to prove that the effects observed are obtained in the precise manner in which radio-active enclosures appear to affect mica. It may be that sufficiently intense $\beta$ radiation may produce effects which in the mineral are almost certainly referable to $a$ rays. Still more protracted observations will be required to differentiate between the rays. However this may be, the cumulative evidence seems to leave no room for doubt that these extraordinary halos are indeed due to radio-activity. In these halos we have, I believe, the only instance so far observed in nature in which the presence of radium can be determined by direct eye observation of a radio-active effect.

Geological Laboratory, Trinity College, Dublin, September 30 .

\section{Apus cancriformis in Great Britain.}

Since the publication of Baird's "Natural History of the British Entomostraca" ( 1850$)$, no record of the occurrence of Apus cancriformis in the British Isles has, so far as I am aware, been published. Mr. Scourfield, in his "Synopsis of the British Fresh-water Entomostraca" (Journ. Quekett Micr. Club, [2], ix., 1904), remarks of this species:-" it is doubtful whether this ought to be included in any modern list of British Entomostraca."

It is therefore of great interest to know that Apus cancriformis, so long lost to observation, has actually reappeared in this country. It was found, during last month, by my friend Mr. Frank Balfour Browne, in some numbers in two small shallow pools on Preston Merse, near Southwick, in Kircudbrightshire. These pools, he believes, may be somewhat brackish, as they are probably occasionally covered by the sea. The specimens which he was good enough to send me were all females, mostly of a good size, and bearing eggs.

Robert GurNeY.

Sutton Broad Laboratory, Catfield, Great Yarmouth. October 6. 